\title{
Osteoarticular Infections in Newborns: Prognostic Factors and Outcome
}

\author{
Aneta Soltirovska Salamon ${ }^{1, *}$, Spela Capuder ${ }^{2}$, \\ Damjana Kljucevsek ${ }^{3}$, Karin Schara ${ }^{4}$, Darja Paro-Panjan ${ }^{1}$
}

\author{
${ }^{1}$ Department of Neonatology, University \\ Children's Hospital Ljubljana, Ljubljana, \\ Slovenia \\ ${ }^{2}$ Department of Pediatrics, General \\ Hospital Celje, Celje, Slovenia \\ ${ }^{3}$ Department of Radiology, University \\ Children's Hospital Ljubljana, Ljubljana, \\ Slovenia \\ ${ }^{4}$ Department of Orthopedic Surgery, \\ University Medical Centre, Ljubljana, \\ Slovenia

\section{*Correspondence} \\ aneta.soltirovska@yahoo.com \\ (Aneta Soltirovska Salamon)
}

\begin{abstract}
Purpose: To analyze clinical, laboratory, microbiologic, imaging and therapeutic data that contribute to outcome in newborn infants with osteoarticular (OSA) infection. Methods: Clinical course, imaging and follow-up data of 15 newborns with the diagnosis of OSA infection were retrospectively reviewed. Results: 15 newborns with 23 acute osteoarthritis foci were included: risk factors were identified in $73 \%$, lower extremities were affected in 8 (53\%) and more than half of the children had two-or multifocal involvement. The predominant causative agent was Staphylococcus aureus. While plain radiography showed osteolytic bone lesions in only $33 \%$, scintigraphy was consistent with osteomyelitis in $74 \%$ of study infants. Magnetic resonance imaging revealed an inflammatory process even when other imaging modalities did not detect any OSA signs. All newborns underwent surgical and antibiotic treatment; the average time from admission to surgical treatment was 3.6 days. No bone and joint deformities or limb-length disturbances were found in the mean follow-up period of 8.5 years. Conclusion: Our study confirms that the most important prognostic factors in predicting a long-term favorable outcome are early diagnosis and therapy consisting of a combination of both surgical and appropriate antibiotic treatment.
\end{abstract}

\section{Keywords}

Osteoarticular infection, Newborn, Osteoarticular imaging, Outcome

\section{Introduction}

Osteoarticular (OSA) infection, although a rare condition, remains a diagnostic and therapeutic challenge and poses the infant at high risk for long-term morbidity [1-3]. The estimated incidence in neonatal intensive units is $1-3$ cases per 1000 admissions [1,2]. There are etiological, clinical, radiological and therapeutic differences between osteoarticular (OSA) infection in the newborn when compared to older children and adults $[4,5]$. In the majority of cases the metaphysis of the long bone are the most commonly implicated sites, but due to the anatomy and blood supply in newborns, osteomyelitis may often spread to the contiguous epiphysis and joint [1]. In the neonatal period, OSA infection usually follows bacteremia, seldom after direct inoculation of bacteria or as a complication of soft tissue infections [5-9]. The diagnostics of OSA may be hindered in neonates, due to the manifestation of less clearcut characteristic symptoms and signs compared to older children [1-3]. When OSA is suspected, imaging techniques used in association with blood and tissue cultures are the most reliable diagnostic tests $[3,10,11]$. While antimicrobial treatment should be administered at the time of clinical suspicion, opinions about surgical treatment are still debatable. Despite modern treatment facilities several studies have documented poor outcome with reported incidence of permanent sequela between $6 \%$ and $50 \%$, including disturbances in bone growth secondary to damage to the cartilaginous growth plate, arthritis, decreased range of motion and pathologic fractures [12-14].

There are only few studies in which OSA has been studied in the neonatal period and the longest follow-up described in neonatal cohorts is $4.5 \pm 1.2$ years [15].

The aim of this study therefore was to analyze clinical 
TA B L E 1. Clinical characteristics of 15 newborns with osteoarticular infection.

\begin{tabular}{|c|c|c|c|c|c|}
\hline Case (n) & Sex & Body weight (g) & Age (day) & Affected joint/bone & Predisposing factor \\
\hline 1 & $\mathrm{~F}$ & 3550 & 14 & L femur d. metaphysis & $\begin{array}{l}\text { acute omphalitis, p. v. catheter- } \\
\text { ization }\end{array}$ \\
\hline 2 & F & 3720 & 22 & $\mathrm{R}$ femur d. metaphysis & paronychia thumb of the $\mathrm{R}$ foot \\
\hline 3 & M & 3750 & 7 & L calcaneus & heel stick blood draws \\
\hline 4 & $\mathrm{~F}$ & 3490 & 27 & $\mathrm{R}$ ulna and radius metaphysis & peripheral v. catheterization \\
\hline 5 & $\mathrm{M}$ & 3170 & 22 & $\begin{array}{l}\mathrm{R} \text { humerus pr. metaphysis and } \\
\text { shoulder art }\end{array}$ & / \\
\hline 6 & M & 3250 & 18 & R tibia d. metaphysis & $\begin{array}{l}\text { early onset sepsis, respiratory } \\
\text { distress }\end{array}$ \\
\hline 7 & $\mathrm{~F}$ & 3800 & 24 & $\begin{array}{l}\mathrm{R} \text { humerus } \mathrm{d} \text { epiphysis and } \\
\text { elbow art }\end{array}$ & $\begin{array}{l}\text { exchange transfusion, umbilical } \\
\text { catheter }\end{array}$ \\
\hline 8 & F & 4370 & 31 & $\begin{array}{l}\text { L femur pr. metaphysis and hip } \\
\text { art }\end{array}$ & l \\
\hline 9 & M & 4165 & 19 & L humerus pr. metaphysis & $\begin{array}{l}\text { clavicle fracture, p. v. catheter- } \\
\text { ization }\end{array}$ \\
\hline 10 & M & 4600 & 30 & $\begin{array}{l}\text { L tibiae pr. metaphysis and knee } \\
\text { art }\end{array}$ & $\begin{array}{l}\text { paronychia of the all four } \\
\text { thumbs }\end{array}$ \\
\hline 11 & $\mathrm{M}$ & 3785 & 19 & $\begin{array}{l}\mathrm{R} \text { femur pr. metaphysis and hip } \\
\text { art }\end{array}$ & l \\
\hline 12 & $\mathrm{~F}$ & 3070 & 9 & L femur d. metaphysis & acute omphalitis \\
\hline 13 & $\mathrm{~F}$ & 3600 & 21 & $\begin{array}{l}\text { L humerus pr. metaphysis and } \\
\text { shoulder art }\end{array}$ & early onset sepsis \\
\hline 14 & $\mathrm{~F}$ & 4220 & 15 & $\begin{array}{l}\mathrm{R} \text { humerus pr. metaphysis and } \\
\text { shoulder art }\end{array}$ & l \\
\hline 15 & F & 2500 & 6 & L shoulder art & p. v. catheterization \\
\hline
\end{tabular}

Art, arthritis; $D$, distal; $F$, female; $L$, left; $M$, male; $P$, peripheral; Pr, proximal; $R$, right; $V$, venous.

data, results of laboratory and imaging investigations and therapeutic management that contributed to long-term outcome in newborns with OSA.

\section{Methods}

A retrospective study included all newborns hospitalized at the Department of Neonatology, University Children's Hospital, Ljubljana, Slovenia, between 1 January 2003 and 31 December 2012, due to the OSA infections. Medical records were reviewed retrospectively for prenatal and perinatal history, clinical presentation, and hospital course including physical assessment, imaging, laboratory and microbiology studies, treatment and follow-up.

Diagnosis of osteomyelitis/septic arthritis was established by clinical appearance (swelling, erythema, pain at movement, decreased range of motion of the involved joint, and/or pseudo paralysis of the involved extremity), results of imaging (plain radiographs, bone scintigraphy, magnetic resonance imaging, and ultrasonography), laboratory and microbiological findings (blood cultures or joint aspiration).

\subsection{Follow-up evaluation}

A regular follow-up by an orthopedic surgeon included clinical and radiological analysis. The first evaluation was performed a month and the second three months after discontinuation of the antibiotic therapy, and were afterwards continued annually; the longest follow-up was 13 years. A favorable outcome was defined if no clinical signs or symptoms, including pain, limited range of motion, limping, limb length or angle deformity were detected. In respect of the radiological evaluation, a favorable outcome was defined if no differences regarding the limb instability, length or angle, and no joint deformities or avascular necrosis were found.

No statistical calculations were performed but rather the absolute numbers of patients with each outcome of interest are reported.

\section{Results}

During the study period, 15 children, $6(40 \%)$ girls and 9 boys (60\%), with OSA infection were identified. Their birth weight ranged from $2500 \mathrm{~g}$ to $4600 \mathrm{~g}$ (mean $3670 \mathrm{~g}$, SD 544.35); gestational age from 37 to 41 weeks (mean 39 
TA B L E 2. Imaging characteristics in 15 osteoarticular infection.

\begin{tabular}{|c|c|c|c|c|}
\hline Case (n) & US & RTG & $\begin{array}{l}\text { Triple-phase bone } \\
\text { scan Tc }{ }^{99 m} \text {-MDP }\end{array}$ & MRI \\
\hline 1 & $\begin{array}{l}\text { soft tissue abscess and } \\
\text { thickened periosteum }\end{array}$ & osteolysis of the d. L femur & $\begin{array}{l}\text { TU in all three } \\
\text { phases }\end{array}$ & nd \\
\hline 2 & $\begin{array}{c}\text { subperiostal and soft tissue } \\
\text { abscess abscess }\end{array}$ & normal & normal & nd \\
\hline 3 & normal & normal & not done & nd \\
\hline 4 & $\begin{array}{l}\text { thickened periosteum, free } \\
\text { liquid } 3 \mathrm{~mm}\end{array}$ & normal & not done & nd \\
\hline 5 & $\begin{array}{l}\text { the shoulder joint effusion, } \\
\text { structurally modified R } \\
\text { humerus metaphysis }\end{array}$ & $\begin{array}{l}\text { rarefication of } \mathrm{R} \text { humerus } \\
\text { pr. metaphysis, hyperemia, } \\
\text { swelling of the soft tissue }\end{array}$ & $\begin{array}{l}\text { TU in all three } \\
\text { phases }\end{array}$ & nd \\
\hline 6 & hypoehogen areal in $\mathrm{R}$ tibia & osteolysis of the R tibia & not done & nd \\
\hline 7 & slightly raised periosteum & $\begin{array}{c}\text { periosteal reaction, swelling } \\
\text { of the soft tissue }\end{array}$ & $\begin{array}{l}\text { TU in all three } \\
\text { phases }\end{array}$ & nd \\
\hline 8 & normal & normal & $\begin{array}{l}\text { TU in all three } \\
\text { phases }\end{array}$ & nd \\
\hline 9 & normal & normal & $\begin{array}{l}\text { TU in all three } \\
\text { phases }\end{array}$ & nd \\
\hline 10 & synovial effusions & osteolysis of the L tibia & not done & $\begin{array}{l}\text { T1 hypointensitive signal in } \\
\text { knee. T1 hypointensitive } \\
\text { and STIR hyperintensive } \\
\text { signal at L tibia metaphysis } \\
\text { and in subperiosteal space }\end{array}$ \\
\hline 11 & $\begin{array}{l}\text { synovial effusions, } \\
\text { thickened synovia }\end{array}$ & osteolysis of the R femur & not done & nd \\
\hline 12 & $\begin{array}{l}\text { thickened synovia in the } \mathrm{L} \\
\text { knee }\end{array}$ & periosteal reaction & $\begin{array}{l}\text { TU in all three } \\
\text { phases }\end{array}$ & nd \\
\hline 13 & minimum synovial effusions & normal & normal & nd \\
\hline 14 & synovial effusions & normal & not done & $\begin{array}{l}\text { T1 hypointensitive signal in } \\
\text { shoulder, soft tissue, wider } \\
\text { axillar recesses. STIR } \\
\text { hyperintensive signal at } \\
\text { posterior and lateral part of } \\
\text { R humerus metaphysis }\end{array}$ \\
\hline 15 & normal & normal & TU in two phases & $\begin{array}{l}\text { T2 hyperintensitive and T1 } \\
\text { hypointensitive signal in L } \\
\text { shoulder and rotator } \\
\text { muscles. Increased uptake } \\
\text { in the synovia and soft } \\
\text { tissue }\end{array}$ \\
\hline
\end{tabular}

$D$, distal; $L$, left; ND, not done; $R$, right; STIR, short T1 inversion recovery sequences; $T U$, tracer uptake.

weeks, SD 1.22). Mean age at admission was 19 days (6 $-31)$ and the duration of symptoms was 1.9 days $(1-3)$. Risk factors for the development of OSA were present in 11 $(73 \%)$ and are in detail presented in (Table 1$)$.

\subsection{Clinical signs and symptoms}

The main presenting findings were irritability and feeding intolerance, followed by a limited range of motion in $87 \%$. In two thirds limb pain and swelling were detected. Temperature was inconsistently present as $47 \%$ had fever. Flexion contracture was present in $27 \%$, pseudoparalysis of the extremity in $20 \%$, and warmth above the area of inflammation in $13 \%$. 


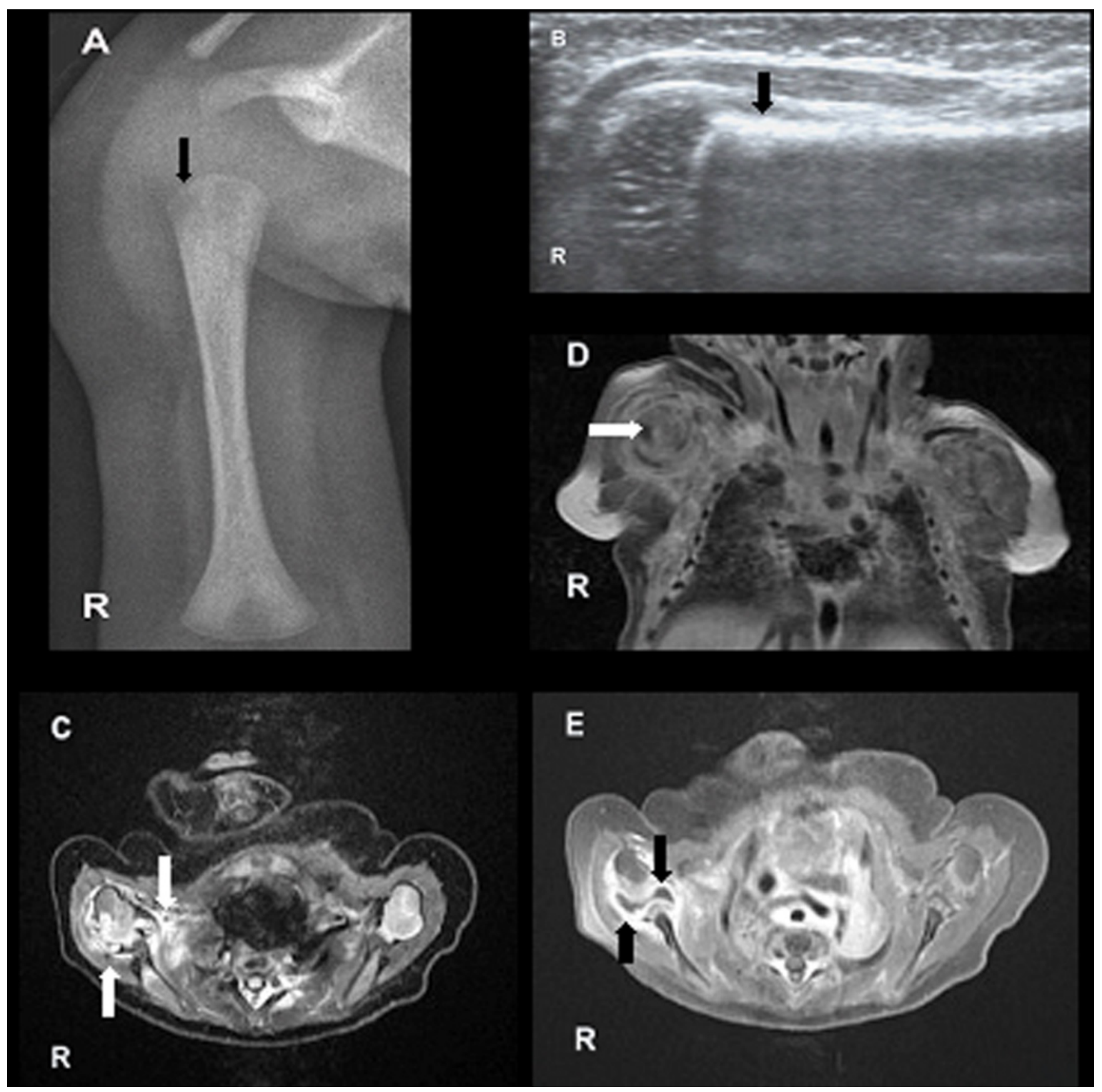

F I G U R E 1. Image course of a 15-day old term newborn with a swollen and painful right shoulder.

A) Radiography of the anteroposterior projection: oedema of the soft tissue of the shoulder and steolytic defects in the metaphysis humerus (arrow). Not ossified epiphysis.

B) Ultrasound with a small oedema around the humerus neck (arrow) and tissue edema.

C) MR STIR of the right shoulder in the transverse plane: pronounced oedema of the soft tissue at the shoulder joint (white arrow) and modified bone signal (black arrow).

D) and E) MRI of the right shoulder T1 TSE FS with contrast media sequence in the coronal and transverse plane: contrast stained soft tissues of the shoulder joint, thickened and hyperemic synovium and effusion (white arrows).

\subsection{Site of involvement}

Unifocal bone and joint involvement was present in 6 newborns while in 9 two or multifocal site of infection was present. Lower extremities were affected more frequently; humerus and femur were the most frequently affected bones. Infection of the bone and joint simultaneously was present in almost half of the cases. All together, there were 23 foci of OSA infections in 15 newborns and in four (Table 1 and Table. 2; cases no. 1, 2, 14 and 15) subcutaneous abscess formation was a sign of underlying OSA infection. Concomitant septic skin metastases were present in only one child (case no. 15).

\subsection{Laboratory and microbiological findings}

As regards inflammatory markers, a C-reactive peptide was elevated in 13 (87\%) infants, non-segmented neutrophils above $10 \%$ were present in one third of newborns and mean thrombocyte count was $481 \times 109 / 1(151-698)$.

Blood culture was performed in all patients and confirmed a bacteriological diagnosis in 9 infants. The predominant causative agent was Staphylococcus aureus (S. 
aureus) in 6 cases, Streptococcus agalactiae in 2 cases and Escherichia coli in one case. Cultures of joint fluid and/or bone tissue were positive in $25 \%$ out of 10 analyzed cases.

\subsection{Imaging}

X-ray of the suspected skeletal region in AP and lateral view was performed in all newborns, but pathological changes were initially seen in a less than one half of newborns [7]: osteolytic lesions were present in 5 and were accompanied by soft tissue edema in 2 children; periosteal reaction was found in 2 cases.

Ultrasonography (US) was performed in all cases and was pathological in 74\%: joint effusion was seen in 5 , thickened periosteum, thickened synovia and changes in the bone in 2; elevated periosteum was seen in one case and subperiosteal abscess in two.

Eight patients underwent triple-phase bone scan with radioactive technetium (Tc-99m). In 6 of them a high tracer uptake was present in all three phases, which is consistent with osteomyelitis. In one child, a high uptake was present only in the first two phases, which is consistent with an abscess in the soft tissue around the shoulder joint (Table. 2). Magnetic resonance imaging (MR), which was performed in 3 newborns, revealed metaphyseal involvement in two; hypointense bone areas on T1-weighted area, hyperintense on fluid sequences with increased uptake after contrast injection (Fig. 1). A joint involvement was identified in all three children. Additionally, a subperiosteal abscess was found in one case and extension into the soft tissue with an abscess was found in two cases.

\subsection{Management and outcome}

All newborns underwent surgical treatment followed by antibiotic therapy for 4-6 weeks. Five newborns were initially treated by empiric antibiotic therapy with cefotaxime and flucloxacillin, and the therapy was subsequently modified according to the results of bacterial sensitivity. Surgical treatment included drainage of pus content and irrigation in the affected bone and/or joint. The average time from admission to surgical treatment was 3.6 days. In 11 newborns surgery was performed in the first 72 hours, and in the remaining 4 , up to five days after the onset of symptoms.

\subsection{Outcome}

The mean follow-up period was of 8.5 years (range 4-13 years), with the longest follow-up of 13 years. All patients were symptom free and no bone or joint deformities or differences in the length of the limbs were observed.

\section{Discussion}

The incidence of OSA infections in this study was 2.7 per 1000 admissions, which is similar to the estimated incidence reported in the literature. Based on the reported study, the frequency of OSA has been the same in the last twenty years, which confirms that this disease remains rare in newborns $[1,14,16,17]$. Although the clinical presentation in the neonatal period is often mild in comparison to OSA infection in childhood, in the present case series, the symptoms and signs played a leading role in the initiation of further diagnostic procedures; all infants had non-specific signs and in the majority, a limited rate of motion was present. Non-specific signs in newborns frequently give rise to the suspicion of bacteremia or sepsis, and as the disease progresses, more specific signs appear, including disability, local swelling, erythema or pain, which limits movement of the involved extremity [3, 16, 18].

In this series, the leading causative organism was S. aureus. There were no cases of methicillin-resistant $S$. aureus as a result of the fact that the prevalence of methicillinresistant strains of $\mathrm{S}$. aureus in the community is less than $10 \%$ and the prevalence of clindamycin-resistant $\mathrm{S}$. aureus $<10 \%$ [19, 20]. Several authors have reported that blood cultures in patients with OSA yield the causative pathogen in approximately $50 \%$, which is similar to our study where $60 \%$ of newborns with OSA infection had a positive hemoculture $[3,18,19]$.

$\mathrm{X}$-ray should always be the initial test in all cases of OSA infections in order to exclude other diagnoses, such as fractures and dislocations, and for follow-ups [19]. Conventional imaging may show early signs of osteomyelitis, while early signs of bone destruction may not be evident on plain radiographs until about 14 days following the onset of symptoms [20]. However, Fisher pointed out that neonates showed signs of bone destruction much earlier than older children, with radiograph abnormalities appearing by 7 to 10 days after the onset of infection [1]. Our results probably comply with his findings, since less than half of the newborns already had pathological findings on X-ray imaging.

Although ultrasonography is regarded as a subjective and very limited method for the assessment of OSA infections, in our study it proved to be a highly sensitive in the detection of soft tissue infiltration, abscess formation and joint effusion early in the process: in two thirds of newborns positive US findings were observed. The value of bone scintigraphy in newborns with OSA has been controversial due to lower sensitivity than in older infants. However, in our study this investigation ruled out OSA inflammation process in all but one case [20-22]. Additionally, in our study it had a discriminative role in making a distinction between bone and soft tissue infection and it was useful in detection of multifocal OSA infections [23]. MR has emerged as the imaging modality of choice for diagnosing osteomyelitis due to its high sensitivity for detecting early infection [1, 18]. Despite the fact that MR was used only in three newborns in our series, this imaging modality had a high sensitivity for the detection of OSA infection, allowing imaging of bone marrow, soft tissue, subperiosteal and articular collections, abscess formation or arthritis.

In the cases presented, children were treated with antibiotics, 4-6 weeks. Peltola and coauthors proposed shorter 
treatment in children older than 3 months, but for newborns a clear recommendation regarding the duration of treatment is still missing and no specific time markers are described in the literature $[3,17,24]$. Surgical drainage is indicated whenever there is collection of pus in the intraarticular space to relieve pressure and to preserve the joint structure [25]. However, the need of drilling the cortex to drain intramedullary collections of the pus remains controversial. In all children from our study surgical decompression, irrigation and drainage were conducted in a very short time after admission to the hospital.

Our study is one of the few in which only newborn infants with OSA were studied, and, to our knowledge, the followup period is longer than in the previous studies. Lee and coauthors studied newborns and infants younger than 18 months with OSA and followed them 74.4 months, while $\mathrm{Li}$ and coauthors studied newborns with septic arthritis and followed them for $4.5 \pm 1.2$ years [15, 26, 27]. As the final outcome may not be clinically apparent until the child reaches 9 or 10 years of age, it is important to follow children after OSA to that age. Contrary to the data in the literature where permanent sequelae following OSA infections were described, in our cohort children had no consequences. The average time from admission to surgical procedure was shorter than 3.6 days. Furthermore, in all infants the duration of disease from the clinical onset to the introduction of antibiotic therapy was shorter than $48 \mathrm{~h}$. Although different factors have been recognized to influence outcome, a therapeutic delay is generally considered an important risk factor for sequelae; a 4-day delay has been suggested acceptable in the treatment of uncomplicated osteomyelitis [18, 28, 29]. Newborns with concomitant septic arthritis and osteomyelitis are especially at risk of long-term functional sequelae $[25,26]$. In the study of 31 infants with septic arthritis of the hip, Lee pointed out that the duration of symptoms longer than 5 days before surgery significantly affected the radiological prognosis [26].

It is usually considered that imaging plays a crucial role in establishing a timely diagnosis and guides early management, with the aim of reducing long-term complications. On the other hand, it is interesting to note that the oldest children in our cohort, who had been diagnosed and treated at the time when we did not have opportunities to perform MRI, had the same favorable outcomes as those in whom imaging with MRI had been performed. Therefore, we can point out that early diagnosis based on full clinical work up, followed by surgery and antibiotic treatment, are essential prognostic components to prevent long-term sequelae.

In conclusion, our cohort of children with long term follow-up after neonatal OSA infection presented with better outcome than that reported in the literature. In comparison to previous studies, the therapy was introduced earlier and consisted of both antibiotic and surgical treatment, so we believe that the most important prognostic factor in predicting long-term outcome in neonatal OSA infection is early diagnosis, followed by both early surgical and antibiotic treatment.

\section{ACKNOWLEDGMENTS}

Thanks to all the peer reviewers and editors for their opinions and suggestions.

\section{CONFLICT OF INTEREST}

All authors declare that they have no conflict of interest.

\section{ETHICAL APPROVAL}

All procedures performed were in accordance with the ethical standards of the institutional and/or national research committee and with the 1964 Helsinki declaration and its later amendments or comparable ethical standards. Informed consent: Informed consent was obtained for all individual participants included in the study.

\section{FUNDING STATEMENT}

No benefits in any form have been received or will be received from a commercial party related directly or indirectly to the subject of this article.

\section{REFERENCES}

[1] Fisher GR. Neonatal Osteomyelitis. Neoreviews.2011;12:374-379.

[2] Knudsen CJ, Hoffman EB. Neonatal osteomyelitis. J Bone Joint Surg Br. 1990;72:846-851.

[3] Muller M, Overturf GD. Bacterial infections of the bones and joints. In: Remington and Klein's Infectious Diseases of the Fetus and Newborn Infant. Edited by Wilson CB, Nizet V, Maldonado Y, Klein JO, Remington JO. 8th edition Elsevier Saunders; 2015; p: 291-307.

[4] Offiah AC. Acute osteomyelitis, septic arthritis and discitis: Differences between neonates and older children. Eur J Radiology. 2006;60:221-232.

[5] Bergdahl S, EkengrenK, Erriksson M. Neonatal hematogenous osteomyelitis: risk factors for long-term sequelae. J Pediatr Orthop. 1985;5:564-582.

[6] Patel NC, Vanchiere JA. Unilateral shoulder swelling in a preterm neonate. Semin Pediatr Infect Dis. 2005;16:70-71.

[7] Sharma RR, Sethu AU, Mahapatra AK, Pawar SJ, Nath A. Neonatal cervical osteomyelitis with paraspinal abscess and Erb's palsy. A case report and brief review of the literature. Pediatr Neurosurg. 2000;32:230-233.

[8] Solebo JO, Keane MR, Obaro RO, Browne LM. Osteomyelitis of head of humerus presenting as Erbs palsy in neonate. Eur J Pediatr. 2004;163:262.

[9] Mohon RT, Mehalic TF, Grimes CK, Philip AGS. Infected cephalhematoma and neonatal osteomyelitis of the skull. Pediatr Infect Dis J. 1986;5:253-256.

[10] Dessi A, Crisafulli M, Accossu S, Setzu V, Fanos V. Osteo-articular infections in newborns: diagnosis and treatment. J Chemother. 2008;20:542-550.

[11] Dich VQ, Nelson JD, Haltalin KC. Osteomyelitis in infants and children. A review of 163 cases. Am J Dis Child. 1975; 129:12731278.

[12] Peters W. Long-term effects of neonatal bone and joint infections on adjacent growth plates. J Pediatr Orthop. 1992; 12:806-810.

[13] Williamson JB, Galasko C, Robinson M. Outcome after acute osteomyelitis in preterm infants. Arch Dis Child. 1990; 65:10601062 . 
[14] Berberian G, Firpo V, Soto A, et al. Osteoartrthritis in neonate: risk factors and outcome. Braz J Infect Dis. 2010;14:413-418.

[15] Li Y, Zhou Q, Liu Y, et al. Delayed treatment of septic arthritis in the neonate: A review of 52 cases. Medicine (Baltimore). 2016;95:e5682.

[16] Yagupsky P, Bar-Ziv Y, Howard CB, Dagan R. Epidemiology, etiology, and clinical features of septic arthritis in children younger than 24 months. Arch Pediatr Adolesc Med. 1995;149:537-540.

[17] Goldmann DA, Durbin WA Jr, Freeman J. Nosocomial infections in a neonatal intensive care unit. J Infect Dis. 1981;144:449-459.

[18] Frederiksen B, Christiansen P, Knudsen FU. Acute osteomyelitis and septic arthritis in the neonate, risk factors and outcome. Eur J Pediatr. 1993;152:577-580.

[19] Somford MP, Huibers MHW, Schuppen J, Struijs PAA, van Lee R. Multifocal Osteomyelitis in a Neonate, an Overview of Diagnosis and Treatment. J Orthop Res Physiothe. 2015;1:015.

[20] Christian S, Kraas J, Conway WF. Musculoskeletal infections. Semin Roentgenol. 2007;42:92-101

[21] Jaramillo D, Treves ST, Kasser JR, Harper M, Sundel R, Laor T. Osteomyelitis and septic arthritis in children: appropriate use of imaging to guide treatment. AJR Am J Roentgenol. 1995;165:399403.

[22] Aigner RM, Fueger GF, Ritter G. Results of three-phase bone scintigraphy and radiography in 20 cases of neonatal osteomyelitis. Nucl Med Commun. 1996;17:20-28.

[23] McPherson DM. Osteomyelitis in the neonate. Neonatal Netw.
2002;21:9-22.

[24] Peltola H, Paakkonen M, Kallio P, Kallilo MJ. Prospective, randomized trial of 10 days versus 30 days of antimicrobial treatment, including a short-term course of parenteral therapy, for childhood septic arthritis. Clin Infect Dis. 2009; 48:1201-1210.

[25] Deshpande SS, Taral N, Modi N, Singrakhia M. Changing epidemiolo $\neg$ gy of neonatal septic arthritis. J Orthop Surg (Hong Kong). 2004; $12: 10-11$.

[26] Lee SC, Shim JS, Seo SW, Lee SS. Prognostic factors of septic arthritis of hip in infants and neonates: minimum 5-year follow-up. Clin Orthop Surg. 2015;7:110-119.

[27] Kabak S, Halici M, Akcakus M, Cetin N, Narin N. Septic arthritis in patients followed-up in neonatal intensive care unit. Pediatr Int. 2002;44:652-657.

[28] Vazquez M. Osteomyelitis in children. Curr Opin Pediatr. 2002;14:112-115.

[29] Ilharreborde B. Sequelae of pediatric osteoarticular infection. Orthop Traumatol Surg Res. 2015;101:S129-137.

How to cite this article: Aneta Soltirovska Salamon, Spela Capuder, Damjana Kljucevsek, et al. Osteoarticular Infections in Newborns: Prognostic Factors and Outcome. Signa Vitae. 2020;16(1):5-11. doi:10.22514/sv.2020.16.0002. 